\title{
Analysis on the Application Situation of China's Smart Logistics from the Perspective of Technology
}

\author{
Zhou Gongjian \\ Xiamen University Tan Kah Kee College, Zhangzhou, Fujian, China \\ 63223748@qq.com
}

Keywords: smart logistics, internet of things, big data, artificial intelligence

\begin{abstract}
The logistics industry is a supporting industry in the national economy. The development of smart logistics can promote the cost reduction and efficiency increase of the entire logistics industry, embody the development trend of modern economic operation, and also have positive practical significance for the current supply-side structural reform. This paper makes an in-depth analysis of the application scenarios of smart logistics technology in logistics, transportation, warehousing and distribution from a technical perspective, and gives a brief overview of the market conditions of logistics technology industry, in order to provide some useful reference and reference for exploring the transformation and upgrading of China's logistics industry.
\end{abstract}

\section{Introduction}

In recent years, under the influence of the rapid development of e-commerce and mobile Internet, the scale of China's logistics market has continued to expand, and some new ideas, new models, new formats, and new technologies have emerged; the trend of fragmentation and decentralization of logistics is becoming increasingly prominent; the core concepts of logistics industry information connectivity, open sharing and intelligence have been widely recognized by the society [1]. On the other hand, because of the impact of the transformation of domestic economic development mode and industrial restructuring, the traditional logistics industry is faced with the constraints of labor, land, capital and other elements and ecological environment. It is a general trend to use the new technology to transform and upgrade all aspects of logistics, reduce costs and increase efficiency, and realize the transformation and upgrading of logistics industry to smart logistics.

As a new logistics format, Smart Logistics has reshaped the relationship between physical factors such as people, goods, vehicles, nodes and lines in logistics with the help of modern logistics technology [2,3]. It closely links the originally separated information flow, logistics, and business flow. and makes the logistics packaging, warehousing, loading and unloading, transportation, distribution and other aspects more intelligent; It breaks through the boundaries between processes and processes in all aspects of commodity circulation, enabling products to be tracked and managed throughout the circulation process, and ensures the network, visualization, timely and intelligent needs of commodity logistics information, thereby effectively reducing logistics costs, improving the quality and efficiency of logistics services, and reshaping the industrial division of labor and resource allocation system.

\section{Research status}

Since the "Smart Logistics" was officially proposed in 2009, Ying Linzhi, Yu Haihong et al. (2011) explained the concept and function of "smart logistics"; Party Jianmin (2013) discusses the importance of developing smart logistics, and gives suggestions on strategic positioning, development model and promotion steps; Wang Zhitai (2014) explained and explored the significance, hand and entry point of developing "smart logistics"; Shao Guangli (2015) explored the smart logistics development model based on Internet of Things technology; Le Hao (2016) explored the characteristics and application prospects of smart logistics and its impact on traditional 
logistics management; Tan Hua, Lin Ke et al. (2016) explored the development trend of smart logistics technology; Hao Shuchi (2017) explored the motivations and countermeasures for developing smart logistics; Ma Bin (2017) explores the application status and trends of modern logistics technology in enterprises; Liu Guofan (2018) explores the impact of logistics technology innovation on the logistics industry.

In summary, most of the existing research results only discuss the characteristics, concepts, development models, meanings, countermeasures and suggestions of "smart logistics"; few discussions have been made on the application scenarios of all aspects of smart logistics from a technical perspective. This paper comprehensively analyzes the technology and application scenarios of each link in the smart logistics industry from the perspective of technology, in order to provide some useful reference and reference for exploring the transformation and upgrading of China's logistics industry.

\section{Smart logistics technology ecological chain}

Modern information technology is the core and foundation of the realization of smart logistics. With the help of modern information technology, logistics enterprises have carried out transformation and upgrading of logistics warehousing, transportation and distribution through resource sharing, information communication and inter-enterprise cooperation to achieve the goal of integrating resources, reducing costs and increasing efficiency [6].

According to the different logistics service links, we divide the technology involved in the smart logistics process into two categories: smart chassis technology and smart operation technology, as shown in Figure 2. Smart chassis technology is the foundation, including the Internet of Things, big data, logistics cloud, artificial intelligence and blockchain; Smart operation technology is applied to the technical practice of all aspects of traditional logistics on the basis of smart chassis technology, mainly including intelligent transportation, intelligent warehousing and intelligent distribution.

\begin{tabular}{|c|c|c|c|c|c|c|c|}
\hline $\begin{array}{c}\text { Intelligent } \\
\text { transportation }\end{array}$ & \multicolumn{6}{|c|}{ Smart storage } & $\begin{array}{l}\text { Intelligent } \\
\text { distribution }\end{array}$ \\
\hline \multirow[t]{2}{*}{$\begin{array}{c}\text { vehicle-to-goods } \\
\text { matching platform } \\
\text { Driverless } \\
\text { New energy vehicle } \\
\text {...... }\end{array}$} & $\begin{array}{c}\text { Storage } \\
\text { auto recognition } \\
\text { Palletizing } \\
\text { robot } \\
\text { …... }\end{array}$ & $\begin{array}{c}\text { Access } \\
\text { AS/RS } \\
\text { AGV handling } \\
\ldots . . .\end{array}$ & $\begin{array}{c}\text { Pick/Sorting } \\
\text { Automatic } \\
\text { sorting robot } \\
\text { Picking robot } \\
\text { ….. }\end{array}$ & \multicolumn{2}{|c|}{$\begin{array}{c}\text { Package } \\
\text { Automatic packaging } \\
\text { Automatic signature } \\
\text {...... }\end{array}$} & $\begin{array}{c}\text { Out of the } \\
\text { library/inventory } \\
\text { RFID } \\
\text { AGV Vision } \\
\text { Split flow } \\
\text { AGV handling } \\
\text {...... }\end{array}$ & $\begin{array}{c}\text { Delivery robot } \\
\text { Drone } \\
\text { Smart express } \\
\text { cabinet } \\
\text { ….. }\end{array}$ \\
\hline & & & $\begin{array}{l}\text { (Smart wor } \\
\text { (Smart chas }\end{array}$ & techn & & & \\
\hline \multicolumn{2}{|c|}{ Internet of Things } & Big Data & \multicolumn{2}{|c|}{ Logistics cloud } & \multicolumn{2}{|c|}{ artificial intelligence } & Blockchain \\
\hline
\end{tabular}

Figure 1 Smart Logistics Technology Ecology Chain

\subsection{Smart chassis technology}

\subsubsection{Internet of Things technology}

The Internet of Things uses the technologies of scanners, positioning systems, radio frequency identification, sensors, data communication, etc. to implement intelligent processing and intelligent control of the basic elements such as carrier, process, fluid, flow, flow rate and flow in the process of logistics operation, thus realizes the controllable, visible and traceable of the whole process of intelligent logistics [4].

In recent years, with the rapid development of the Internet and the large number of applications of sensors, the Internet of Things has shown a rapid growth trend in China, laying a solid foundation for the development of smart logistics. Typical application scenarios include: 
(1) Product traceability: Through RFID, the functions of tracking, querying, identifying, information collecting and visualizing the information of all aspects of product production, transportation and delivery are realized.

(2) Dispatching monitoring: using GPS, sensing technology and RFID to achieve vehicle positioning, online scheduling, safe transportation, cold chain control, transportation item monitoring and distribution management.

(3) Path optimization: The information of the transportation vehicle status, road conditions, weather, etc. is collected by the information collection equipment installed on the vehicle, and then uploaded to the information center for analysis and optimization of the path scheduling of the vehicle.

\subsubsection{Big data technology}

The onlineization of logistics will generate a large amount of data, use big data technology to analyze, process and mine logistics big data, find valuable information for business operation and management, and then make more scientific and reasonable management decisions [5]. At present, many domestic logistics companies have established big data analysis teams or departments to conduct research, analysis and application layout of big data technology to strengthen the analysis and forecast of risks in all aspects of logistics. Typical application scenarios include:

(1) Demand forecasting: Using advanced algorithms to collect and analyze historical data such as merchant sales and user consumption characteristics, predict user demand, and arrange warehousing and transportation in advance.

(2) Equipment maintenance forecast: By installing an integrated chip on the IoT device, the operating status of the device is monitored in real time, and the device is pre-maintained through big data analysis to increase its service life.

(3) Supply chain risk prediction: Through the collection and analysis of abnormal data in the supply chain, the damage and trade risks caused by force majeure factors are predicted and circumvented.

(4) Network optimization layout: The network analysis model is constructed by using the coverage and timeliness of historical data to Optimize and layout the logistics, transportation and distribution of logistics. For example, through the analysis of consumer data, stocking in the warehouse closest to the consumer in advance; through real-time route optimization, guiding transport vehicles to use the best route for city-to-city distribution and cross-city transportation.

\subsubsection{Logistics cloud technology}

Logistics cloud technology is divided into two parts: cloud storage and cloud computing. It is the basis and guarantee for the implementation of logistics big data. Logistics cloud can efficiently integrate, schedule and manage resources, and provide algorithm application and information system services for intelligent logistics participants on demand. In recent years, logistics service providers represented by rookie and Jingdong have launched their own logistics cloud services [7]. Typical application scenarios include:

(1) Software as a Service (SAAS): SAAS of information systems such as order management, warehouse management and transportation management, which provides more diversified and fast service iterative upgrades for information management systems of related enterprises.

(2) Coordinating resources: Integrate resources such as idle distribution personnel, warehouses and vehicles in the society, and maximize the utilization of resources by rationally analyzing the equipment usage status, human resources and warehouse leasing.

(3) Algorithm componentization service: componentize the algorithm of vehicle scheduling, packing, route optimization and consumables recommendation, and provide combined or single algorithm application service for logistics enterprises.

\subsubsection{Artificial intelligence technology}

The artificial intelligence technology of the logistics industry mainly focuses on the fields of intelligent search, reasoning planning, intelligent robots, etc. It can intelligently empower the 
logistics links, realize the intelligent allocation of logistics resources and the high efficiency of logistics operations [6]. Typical application scenarios include:

(1) Intelligent operation rule management: Through the deep learning of the machine, the logistics operation rule engine has the ability of self-adaptation and self-learning, and can carry out self-management and decision-making after sensing the logistics business conditions. For example, through the comparative analysis of the peak period (e-commerce double eleven) and the normal order, the operating rules such as delivery aging, order production mode, abnormal order processing, and freight are set autonomously.

(2) Intelligent warehouse location: self-learning on the availability of labor in the real environment, taxation system, geographical location of customers, suppliers and producers, construction costs, transportation economy, etc., and giving the best location plan for the logistics warehouse From the decision-making.

(3) Intelligent decision-making assistance: machine learning is used to automatically identify the state of objects, people, vehicles and equipment inside and outside the yard, and to learn the excellent management and operation command and decision-making experience of the actual operation, and realize the intelligent decision-making assistance of the freight yard.

(4) Image recognition: The convolutional neural network and computer image recognition technology are used to improve the recognition rate and accuracy of the handwritten waybill, which can greatly reduce the error rate and workload of the manual order.

(5) Intelligent scheduling: Through the analysis and learning of the volume, quantity, category and other data of the commodity, the intelligent packaging of the packaging, warehousing, transportation and distribution of the logistics is carried out. For example, using the deep learning algorithm to measure the package size and volume data of millions of SKU products, intelligently recommend the consumables and packaging sorting required for the goods, and then rationally arrange the merchandise placement and the box type.

\subsubsection{Blockchain technology}

Blockchain is a new application mode combining computer technology such as encryption algorithm, distributed data storage, consensus mechanism and point-to-point transmission; its essence is an intelligent peer-to-peer network that uses distributed databases to record, disseminate and identify information; its distinctive features are decentralization, openness, autonomy and consensus, information cannot be tampered with and traceable, transactions are transparent and anonymous [7].In recent years, with the rapid development of blockchain technology around the world, many industry insiders believe that the application of blockchain technology will have a profound impact on the development of smart logistics. Typical application scenarios include:

(1) Guarantee the safety of goods: Through the blockchain technology, the whole process of goods circulation is recorded in a true and reliable way, ensuring traceability of information, avoiding the occurrence of events such as packet loss, forgery of signatures, and misleading of the courier delivery.

(2) Implementing the real-name system of logistics: The logistics data mastered by the blockchain technology cannot be modified, which can effectively prevent the adjustment and unloading of goods, and facilitate the implementation of anti-counterfeiting and real-name system of logistics.

(3) Improve the business environment of the logistics industry: Through the blockchain technology, the value and assetization of logistics goods can be realized, and then the funds can be quickly and effectively connected to the logistics industry, thus solving the financing difficulties of small and medium-sized logistics enterprises.

\subsection{Smart work technology}

\subsubsection{Smart storage}

Driven by smart logistics technology, the warehousing industry is becoming more automated and intelligent, automation can improve efficiency, intelligence can meet the needs of differentiation 
and individualization, and enhance supply chain flexibility. For example, a complete intelligent warehousing system requires a fully automated warehousing system to integrate, share, track, and mine warehousing information to achieve accurate order processing, seamless entry and exit, and automated pick-up operations; in terms of hardware, AGV robots, RFID tags, stereoscopic warehouses, and palletizing robots complete the loading, labeling, picking, and packing of goods.

\subsubsection{Intelligent transportation}

The transportation link mainly involves new energy vehicles, vehicle-matching platforms, and unmanned driving technologies. For example, the vehicle-to-goods matching platform uses Internet technology to effectively integrate and dock distributed vehicles and sources through APP, WEB, etc., so as to realize real-time sharing and two-way accurate matching of freight supply and demand information; it resolves the dilemma of car-information information islands, reduces the air-driving rate, saves transportation costs, and improves the operational efficiency of the trunk transportation industry [4].

At present, a large number of cargo matching platforms represented by Yunmanchu, cargo pull, and card world are actively exploring the market, accumulating and precipitating user data, and striving to build an integrated ecosystem of road transport.

\subsubsection{Intelligent distribution}

In order to realize the distributed layout and shared utilization of logistics resources, the terminal human resources, service network and intelligent terminals are integrated through the Internet platform, and the urban terminal distribution capacity pool is built; which adopts the mode of centralized distribution, intelligent distribution and common distribution to realize distributed distribution and shared utilization of resources, eliminating the "last mile" distribution problem [6].

Taking the intelligent express cabinet as an example, its structure is divided into a background management system and a storage terminal, which utilizes technologies such as the Internet of Things, intelligent identification, and wireless communication to realize operations such as information management, intelligent pickup, smart storage, information distribution, and remote monitoring.; which effectively solves the pain points of delivery for the last 100 meters. At present, the domestic intelligent express cabinet market is fiercely competitive, which mainly includes: ecommerce companies represented by Jingdong and Suning; express companies represented by Fengchao and Post E-mail; and third parties represented by Express, Yishun and Yun Cabinet.

\section{Analysis of logistics technology industry}

Through in-depth analysis of the domestic logistics technology industry, we find that all types of commercial enterprises rely on their own characteristics and advantages, and actively deploy smart logistics technology areas, trying to seize market opportunities.

(1) E-commerce platform-type logistics enterprises (such as Ali, JD, Amazon, etc.): Relying on the advantages of their own Internet technology genes, focus on improving the overall operational efficiency of logistics through technical means; By actively deploying in emerging technology fields, they strive to achieve over-the-counter overtaking of traditional logistics companies, and their technology maturity and technology dependence are relatively high.

(2) Leading logistics companies (such as SF, UPS, DHL, etc.): Actively deploy in logistics emerging technologies by forming technical R\&D teams or working with leading third-party R\&D institutions; however, due to its own data disadvantage, at present, there is a certain gap between artificial intelligence and big data applications compared with e-commerce logistics enterprises.

(3) Smart logistics service-oriented enterprises (such as G7, Yunmanchu, etc.): Focusing on the development and service of big data, Internet of Things and artificial intelligence platforms, it has strong technical strength and business model advantages; with the help of professional R\&D team with Internet thinking and venture capital, its development prospects are huge. 


\section{Conclusion}

At present, China is in the critical period of a new round of industrial transformation. The use of new technologies to develop smart logistics is an important measure for the logistics industry to transform its economic development mode and industrial structure transformation and upgrading. For logistics companies, in the face of new trends in the times, whether they can occupy a dominant position in the future market competition, which need to grasp the following success factors:

(1) Embracing wisdom: Logistics companies need to combine their own characteristics and changes in customer characteristics in their fields, embrace technology and smart logistics with an open mind, and achieve transformation and upgrading.

(2) Advance layout: Smart logistics is no longer a multiple-choice question. Under the wisdom of the wind, who can grasp the opportunity, who can take the initiative, logistics enterprises need to lay out in advance to seize the wisdom of logistics opportunities.

(3) Emphasis on data: Data is the key to the logistics industry to upgrade to the next generation, truly realize smart logistics; although traditional logistics companies have natural disadvantages in data acquisition, they can try to cooperate with third-party logistics service companies to accumulate technologies in artificial intelligence, big data, and Internet of Things, and actively upgrade existing logistics information systems.

\section{Acknowledgements}

This paper is one of the phased results of the Design of the 13th Five-Year Education Science Planning Project in Fujian Province (FJJKCGZ16-165).

\section{References}

[1] Liu Guobiao. Measurement and Path Analysis of Logistics Technology Innovation Impact on Logistics Industry_—Based on the Data Model of Inter-provincial Space Dubin Panel from 2000 to 2015[J].China Circulation Economy.2018,(1):38-46.

[2] He Liming. The development trend of China's smart logistics [J]. China's circulation economy. 2017, (6): 3-7.

[3] Chen Hai. Research on Logistics Innovation Path Based on Information Technology [J]. Logistics Engineering and Management. 2015, (3): 101-104.

[4] Tan Hua, Linke. Analysis of hotspot technology and application development of Internet of Things [J]. Mobile Communications. 2016, (17): 64-69. http://www.50cnnet.com/ show-94-991751.html

[5] China Securities Network. Big data for supporting intelligent logistics to accelerate development [EB/OL]. (2016-06-21) [2018-01-15]. http://www.50cnnet.com/ show-94 -99175-1.html

[6] Deloitte Research Institute. China Smart Logistics Development Report [EB/OL]. (2018-01-08) [2018-01-15]. http://www.cbdio.com / BigData/2018-01/08 /content_5481903.htm

[7] iResearch. 2017 China Logistics Technology Industry Research Report [EB/OL]. (2017-1024)[2018-01-15]. http://www.sohu.com/a/199915720_483389 